\title{
EFEITO DO FOGO SOBRE A MIRMECOFAUNA NO PARQUE NACIONAL DA CHAPADA DIAMANTINA, BAHIA, BRASIL.
}

\section{$\underline{\text { Juliana Santos Carneiro }}^{1}$ e Evandro do Nascimento Silva ${ }^{2}$}

1. Bolsista PIBIC/FAPESB, Graduando em Ciências Biológicas, Universidade Estadual de Feira de Santana, e-mail: carneiroj11.2@gmail.com

2. Orientador, Departamento de Ciências Biológicas, Universidade Estadual de Feira de Santana, e-mail: evandro.ecology@gmail.com

PALAVRAS-CHAVE: formigas, efeitos antrópicos.

\section{INTRODUÇÃO}

O fogo é um dos tipos mais importantes de perturbação que afeta a vegetação tropical de montanha (Gonçalvez et al 2011; Sherman et al 2012). Distúrbios são uma importante fonte de heterogeneidade espacial e temporal na estrutura e dinâmica das comunidades naturais (Sousa, 1984). O efeito de uma perturbação na diversidade biológica depende das proporções da própria perturbação (Townsend et al, 1997; McCabe \& Gotelli, 2000), do estado inicial do ecossistema (Christensen, 1993; Foster et al., 1998), e das condições bióticas e abióticas (Foster et al., 1998). Estudos dedicados aos efeitos do fogo sobre as comunidades de formigas mostram que a diversidade de formigas pode exibir várias tendências após o fogo, aumento ou baixa da abundância e riqueza de espécies, alta ou baixa mortalidade (Jackson \& Fox, 1996; Folgarait, 1998; York, 2000), de acordo com ambas as condições bióticas e abióticas.

A Chapada Diamantina é uma das regiões da Bahia mais afetadas pelas constantes queimadas, demandando grande aporte de recursos financeiros e humanos para os combates aos incêndios. O Parque Nacional da Chapada Diamantina (PNCD) está localizado em uma região montanhosa do nordeste do Brasil, onde muitas espécies endêmicas ocorrem dentro de ecossistemas de campos e savanas, especialmente em campos rochosos conhecidos como campos rupestres, onde os fogos antropogênicos são recorrentes (Gonçalvez et al. 2011).

O fogo é um dos distúrbios mais comuns que podem causar grande escala de mudanças na diversidade de espécies e, portanto, tem atraído considerável esforço de pesquisa (Whelan, 1995). As formigas são insetos abundantes e bem distribuídos que são consideradas importantes no funcionamento do ecossistema. Elas podem desempenhar um papel central em processos como a ciclagem de nutrientes, dispersão de sementes e a regulação da população de outros insetos (Hölldobler \& Wilson, 1990; Folgarait, 1988). Portanto, este trabalho justifica-se em função a falta de pesquisa nessa área e a necessidade de um estudo sobre o efeito do fogo nas comunidades de formigas em campo rupestre na Chapada Diamantina. Outra justificativa é que o estudo está inserido em um PELD, Projeto Ecológico de Longa Duração, e gerará uma linha de base no tempo inicial da perturbação fogo, permitindo um monitoramento da evolução da restauração ecológica da mirmecofauna ao longo do tempo após uma perturbação ecológica. Os resultados de presente trabalho poderão ser utilizados para criar meios de conservação deste habitat.

\section{MATERIAL E MÉTODOS}

Área de estudo - $\mathrm{O}$ estudo foi realizado no Parque Nacional da Chapada Diamantina ( $\left.12^{\circ} 52^{\prime} 49^{\prime \prime} \mathrm{S} 41^{\circ} 22^{\prime} 20^{\prime \prime} \mathrm{O}\right)$, situado na região central da Bahia. A área da coleta está localizada entre os municípios Mucugê-Ibicoara (Larga de Cima). Essas localidades são caracterizadas por apresentarem vastos platôs, acima de 900 metros de 
altitude, compostos por uma matriz de vegetação campestre sobre solos arenosos, rasos e comportando inúmeros afloramentos rochosos. $\mathrm{O}$ desenho experimental consistiu em uma parcela de $50 \times 50$ metros.

Coleta de dados - Para caracterizar a comunidade de formigas foram utilizados os métodos de coleta que são recomendados no Ants of the Leaf Litter Protocol - ALL Protocol - proposto por Agosti e Alonso (2001), exceto que não foi coletada serrapilheira, a qual não é formada densamente em campos rupestres. Para que houvesse melhores resultados foram utilizados dois métodos de coleta, que foram realizadas em duas campanhas, uma em outubro de 2015 antes da queimada e outra após, em fevereiro de 2016. 1 - Armadilhas tipo Pitfall - foram instaladas 60 armadilhas pitfalls com álcool $70 \%$, que permaneceram no local por 48 horas. 2 - Armadilha com isca de sardinha ou mel - foram instaladas 60 armadilhas de isca, que foram retiradas em 1 hora. As armadilhas com iscas foram dispostas em uma grade de cinco linhas separadas por $5 \mathrm{~m}$ de distância dentro e entre as linhas. A triagem, montagem e morfo-especiação, ocorreram no Laboratório de Entomologia da Universidade Estadual de Feira de Santana. A riqueza da comunidade foi mensurada em nível taxonômico de gênero, tendo em vista ainda não ter sido possível a identificação dos espécimes coletados em nível de espécie.

Análise de dados - A riqueza de espécies foi estimada através da elaboração de curvas de acumulação de espécies, utilizando-se o software EstimateS e a similaridade foi calculada pelo Índice de Jaccard. Uma análise não-paramétrica, pelo teste do Quiquadrado, foi realizada com o software Bioestat 5.0 para as frequências de ocorrência das espécies mais abundantes de formigas, antes e após o fogo.

\section{RESULTADOS E DISCUSSÃO}

Os resultados obtidos mostraram um grande aumento na abundância de formigas após a perturbação de fogo (três meses depois). Em várias amostras nas quais não foram coletados espécimes de formigas na primeira coleta, antes do fogo, ocorreu a captura de formigas na segunda coleta. Uma explicação para isso é que após o fogo algumas barreiras que impedem o forrageamento são eliminadas (Andersen, 1988), o que possibilita às formigas maior alcance dos recursos alimentares. Outra explicação seria o aumento de recursos tróficos após o fogo, uma vez que o rebrotamento da vegetação causa a oferta de nectários extraflorais, bem como traz a presença de homópteros que são atendidos por formigas, as quais podem coletar honeydew (exsudato da excreção dos homópteras rico em carboidratos), o que foi observado em campo.

\section{Diversidade de Gênero - Todos os métodos}

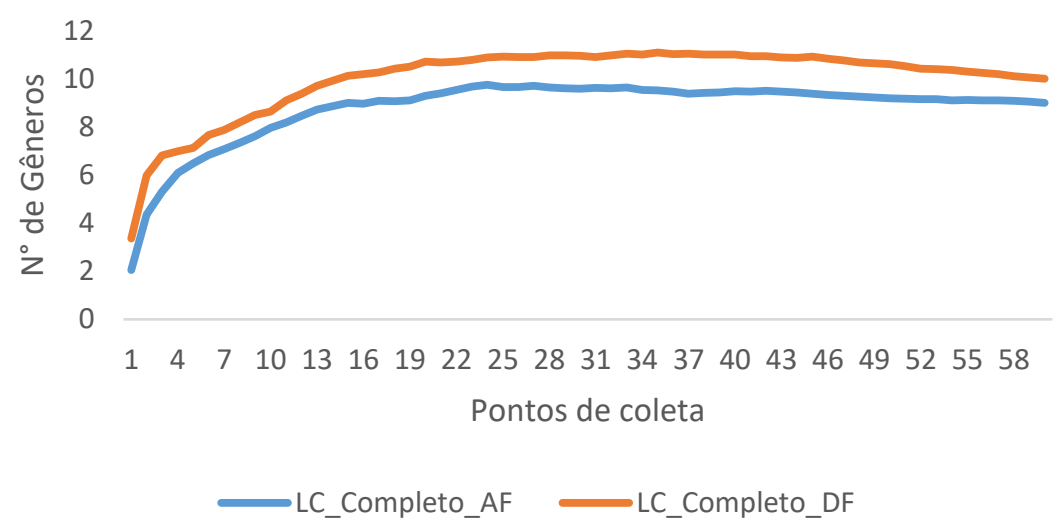

Figura 1: Diversidade de gêneros, com todos os métodos de coleta, por pontos. LC - Larga de Cima; AF - Antes do fogo; DF - Depois do fogo. 
A análise de diversidade beta, ou seja, similaridade de Jaccard entre comunidades, antes e após o fogo, mostrou que nas armadilhas do tipo pitfall a similaridade entre as comunidades nos dois tempos observados foi de 0,666. Esse índice refletiu a ocorrência de três gêneros de formigas após o fogo, os quais não ocorreram, nas amostras coletadas antes do fogo. Nas iscas de sardinha, a similaridade foi de 0,71. Neste caso, um gênero que ocorreu antes do fogo não estava presente nas amostras coletadas após o fogo, e vice-versa. Essa situação na composição dos gêneros também ocorreu nas iscas de mel, nas quais o índice de similaridade foi de 0,666. Tais índices de similaridade não demostram mudanças drásticas na composição de gêneros nos grupos tróficos de formigas forrageadoras de proteína e forrageadoras de fontes de carboidratos. Mas os resultados das coletas com pitfall mostram que, no geral, a ocorrência de fogo possibilitou o surgimento de gêneros que não estavam presentes antes do fogo. Para justificar esse acréscimo de gêneros em relação aos outros métodos de coleta usamos o tempo, pois a armadilha do tipo pitfall permanece em campo 48 horas e as armadilhas com iscas apenas 1 hora. Quanto maior for tempo que a armadilha ficar exposta em campo, maior será a chance de capturar mais espécimes.

$\mathrm{O}$ aumento na frequência de captura de formigas no segundo período de coleta foi observado para dois dos três tipos de armadilhas (pitfall, mel e sardinha). Para a armadilha de queda, pitfall, não houve diferença significativa da frequência de captura do que o esperado ao acaso $(\chi 2=2,15 ; \mathrm{gl}=1 ; \mathrm{p}=0,14)$. Na coleta antes do fogo em $85 \%$ das amostras foram coletadas formigas, e após o fogo 93\%. Para a armadilha com isca de sardinha, antes do fogo, em $45 \%$ das amostras haviam formigas, e após o fogo $93 \%$, uma diferença de frequência significativamente maior do que o esperado ao acaso $(\chi 2=32,86$; $\mathrm{gl}=1 ; \mathrm{p}<0,0001)$. Para a isca com mel, a diferença na frequência de formigas foi significativamente maior que o esperado ao acaso $(\chi 2=45,68 ; \mathrm{gl}=1 ; \mathrm{p}<0,0001)$, com ocorrência de formigas em $31 \%$ das amostras coletadas antes do fogo, e $91 \%$ de amostras com presença de formigas após o fogo. Entre as iscas, a abundância e a riqueza de gêneros de formigas sempre foram maiores para a sardinha, o que também foi verificado por Frizzo (2012).

Esses resultados são relevantes contribuições ao conhecimento dos efeitos do fogo sobre a diversidade faunística no PNCD. Os efeitos do fogo sobre comunidades bióticas devem ser estudados como forma de subsidiar ações de conservação biológica em ecossistemas sujeitos a tais perturbações. Recentemente, o PNCD sofreu um processo intenso de incêndios. Os impactos desses eventos estocásticos sobre a biodiversidade da unidade de conservação ainda não são conhecidos. Este estudo indica que nem todos os táxons são severamente afetados em sua abundância e composição da comunidade.

\section{CONCLUSÕES}

Os resultados mostram que a comunidade de formigas pode ter aumento da abundância e riqueza de formigas, bem como alterações na composição da comunidade. A perturbação pelo fogo, com base nos dados obtidos, não comprometeu a estrutura da comunidade de formigas. Esta análise é preliminar, baseada em nível taxonômico de gênero. A confirmação será necessária quando a identificação dos espécimes coletados for efetuada em nível de espécie.

\section{REFERÊNCIAS}

AGOSTI, D. e ALONSO, L.E., (2001). The all Protocol: a standard protocol for the collection of ground-dwelling ants. Anet Newsletter, vol. 3, p. 8-11. 
ANDERSEN, A.N. (1988) Immediate and longer-term effects of fire on seed predation by ants in sclerophyllous vegetation of southeastern Australia. Australian Journal of Ecology, 13, 285-293.

CHRISTENSEN, N.L. (1993) Fire regimes and ecosystems dynamics. Fire in the environment: the ecological, atmospheric, and climatic importance of vegetation fires (ed. by P.J. Crutzen and J.G. Goldammer), pp. 233-244. Dahlem Workshop Reports. Environmental Sciences Research Report 13, John Wiley and Sons Ltd, Chichester.

FOLGARAIT, P.J. (1998) Ant biodiversity and its relationship to ecosystem functioning: a review. Biodiversity Conservation, 7, 1221-1244.

FOSTER, D.R., KNIGHT, D.H. \& FRANKLIN, J.F. (1998) Landscape patterns and legacies resulting from large, infrequent forest disturbances. Ecosystems, 1, 497-510.

FRIZZO, T. L. M., CAMPOS, R. I. \& VASCONCELOS, H. L. (2012). Contrasting Effects of Fire on Arboreal and Ground-Dwelling Ant Communities of a Neotropical Savanna. BIOTROPICA 44(2): 254-261.

HOLLOBLER, B. \& WILSON, E.O. (1990) The ants. Cambridge University Press, Cambridge.

GONÇALVEZ, C.N.; MESQUITA, F.W.; LIMA, N.R.G.; COSLOPE, L.A. \& LINTOMEN, B.S. (2011). Recorrência dos incêndios e fitossociologia da vegetação em áreas com diferentes regimes de queima no Parque Nacional da Chapada Diamantina. Biodiversidade Brasileira 1: 161-179.

JACKSON, G.P. \& FOX, B.J. (1996) Comparison of regeneration following burning, clearing or mineral sand mining at Tomago, NSW: II. Succession of ant assemblages in a coastal forest. Australian Journal of Ecology, 21, 200-216.

McCABE, D.J. \& GOTELLI, N.J. (2000) Effects of disturbance frequency, intensity, and area on assemblages of stream macroinvertebrates. Oecologia, 124, 270-279.

SHERMAN, R.E.; FAHEY, T.J.; MARTIN, P.H. \& BATTLES, J.J. (2012). Patterns of growth, recruitment, mortality and biomass across an altitudinal gradient in a neotropical montane forest, Dominican Republic. Journal of Tropical Ecology 28: 483-495.

SOUSA, W.P. (1984) The role of disturbance in natural communities. Annual Review of Ecology and Systematics, 15, 353-391.

TOWNSEND, C.R., SCARSBROOK, M.R. \& DOLEDEC, S. (1997) The intermediate disturbance hypothesis, refugia, and biodiversity in streams. Limnology and Oceanography, 42, 938-949.

WHELAN, R. (1995) The ecology of fire. Cambridge Studies in Ecology. Cambridge University Press, Cambridge.

YORK, A. (2000) Long-term effects of frequent low-intensity burning on ant communities in coastal black butt forests of southeastern Australia. Austral Ecology, 25, 83-98. 